\title{
Educational Leadership Preparation: What Supervisors, Candidates, And Mentors Said
}

J. Eric Tubbs, Kennesaw State University, USA

H. E. Holliday, Kennesaw State University, USA

\begin{abstract}
The findings of this study identified practicum areas that meet the educational demands of candidates while highlighting practicum areas that need improvement. The study contributes to the knowledge base of the field by drawing upon feedback from university supervisors, school mentors and program candidates to evaluate and improve the practicum experience in the educational leadership program. Program candidates are in the best position to discuss their recent experiences of exposure to the real world. Supervisors and mentors can witness from their first hand experience how effective practicum activities work. Responses from supervisors, mentors and candidates regarding leadership practicum experiences are valuable to program developers in their future program redesign effort. Practicum experiences expose candidates to real-world school leadership experiences. Unfortunately, because of all kinds of conditional limitations, such practicum experiences can only be offered in conjunction with candidates' regular work in school. However, leadership practicum experiences can be well planned with a high collaboration of supervisors, mentors and candidates who have an invested interest in school improvement. In this study, what we learn from the differences of perceptions among supervisors, mentors and candidates is a caution to all stakeholders that we need to do a better job to prepare the next generation of school leaders. Supervisors, mentors and candidates need to form a coalition to explore other options, especially out-of-the-box strategies, to deliver a highly effective practicum program for potential educational leaders.
\end{abstract}

Keywords: Educational Leadership Preparation Programs, Internship, Practicum, and Leadership Development.

\section{INTRODUCTION}

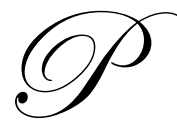

racticum experience is an important component of an educational leadership preparation program. It is designed to expose program candidates to the practical work in the real world of educational leadership. Implementation of the two semester practicum experience involves three stakeholders at a large southeastern public university: university professors as supervisors, school administrators as mentors, and program candidates. The stakeholders' perceptions of the practicum experience are most valuable for continuous improvement of the educational leadership program. The professional literature abounds with programs and research promoting ways to improve the quality of Educational Leadership preparation programs. Promising practices have included engaging in thorough and honest review (Gupton, 1998), listening to the participants and attending to their individual needs (Crews \& Weakley, 1995), understanding how adults learn (Daresh, 1997), fostering the development of appropriate dispositions (Lee \& Keiffer, 2003), understanding and recognizing the difficult transition first-year administrators must face (Henderson, 2002), and being more outcome based (Laing \& Bradshaw, 2003).

Those seeking to strengthen their programs may also wish to look at the importance of mentoring (Kraus, 1996), networking (Parkay \& Currie, 1992), restructuring the administrative internship program (Gantner \& Halsall, 2003), and call for preparation to be a partnership or collaboration between universities and the public schools. 
Tubbs (2008) noted that field experiences in educational leadership bridge the gap between classroom theory and professional practice. In addition, activities in practicum experiences should link theory to. Research findings suggest that field experiences can best be completed in phases (Cordeiro and Smith-Sloan, 1995). Specifically, Jackson and Kelley (2002), and Joachim and Klotz (2000) identified areas of educational leadership that needed to be covered in the field experiences. Further, Tubbs (2007) recommended that practice programs focus on what principals would actually do in a given circumstance, rather than what they might do. Bradshaw, Perreault, McDowelle, and Bell (1997) concluded in their study that candidates of full-time extended internship were better prepared for entry-level administrative positions than their part-time counterparts. Therefore, this study attempts to address the perceptions of the effectiveness of practicum experience from the viewpoint of different stakeholders.

\section{Purpose of the Study}

The purpose of this study is to investigate how effective practicum experience in an educational leadership program is in serving the purpose of preparing educational leaders for future challenges. Strengths and weaknesses of the practicum experience would be identified through the perceptions of supervisors, mentors and program candidates. Findings of this study would confirm program areas that met the educational demands and highlight areas that would need improvement to make the practicum experience more effective.

Further, Creighton (2001) recommended that practice programs focus on what principals would actually do in a given circumstance, rather than what they might do. Bradshaw, Perreault, McDowelle, and Bell (1997) concluded in their study that candidates of full-time extended internship were better prepared for entry-level administrative positions than their part-time counterparts. Chance (1990) also found that the impact of practicum on future administrators was somewhat limited.

These findings indicate a link between practicum experiences and the overall effectiveness of the leadership program. However, few studies are found regarding the perceptions among the stakeholders. Therefore, this study will attempt to address the effectiveness of the practicum experience from the viewpoint of different stakeholders.

\section{Research Questions}

1. How do university supervisors perceive the effectiveness of practicum experience in the educational leadership program?

2. How do school mentors perceive the effectiveness of practicum experience in the educational leadership program?

3. How do program candidates perceive the effectiveness of practicum experience in the educational leadership program?

4. Do university supervisors, school mentors and program candidates differ significantly in their perceptions of the effectiveness of practicum experience in the educational leadership program?

5. Do gender, ethnicity, leadership experiences and school level make any difference in supervisors', mentors' and candidates' perception of the effectiveness practicum experience in educational leadership program?

\section{METHODOLOGY}

\section{Research Design}

The study was designed to take both quantitative and qualitative approaches. Program candidates, their university supervisors and school mentors were surveyed to solicit their perceptions of the effectiveness of leadership practicum experiences. The researchers believe that the use of both approaches will present a more holistic picture of the quality of practicum which participants recently experienced. Quantitative and qualitative data would also help the researchers to achieve a triangulation purpose. 


\section{Participants}

In the spring semester of 2008, ninety candidates in an educational leadership program who participated in practicum experiences were surveyed with 83 responses (92.2\%). All full-time and part-time faculty members who supervised practicum candidates were invited to participate in the study. A total of 17 faculty members $(70.8 \%)$ responded to the survey. Forty-four candidates' school mentors were invited to participate with 13 responses $(29.4 \%)$.

\section{Research Instruments}

The researchers designed a survey instrument based on the Educational Leadership Constituent Council Standards (ELCC) which solicited the candidates' perceptions of their practicum experience. The first part of the survey called for certain demographic variables regarding the survey respondents. The next 17 items were related to participants' perceptions of the extent to which they agreed with the effectiveness of practicum activities. The last part in the survey consisted of 7 open-ended questions to solicit qualitative comments from the participants relating to their practicum experiences. Two other corresponding instruments were constructed to reflect the same items from the perspectives of university supervisors and the school mentors. All three instruments were professionally examined in contents, format and language by pilot testing with a randomly selected sample of program candidates, supervisors and mentors. All constructive recommendations were incorporated in revising the instruments. All pilot data were tested for internal inconsistencies with alpha $=.94$ (candidates' survey), alpha $=.966$ (supervisors' survey), and alpha $=.959$ (mentors' survey).

\section{Data Analysis}

Quantitative data were analyzed by descriptive statistics: percentages, means and standard deviations. Comparison was made by ANOVA to determine if differences existed among candidates, supervisors and mentors in their perceptions of practicum experiences. All participants' responses were also analyzed by ANOVA to consider if gender, ethnicity, leadership experiences and school level made any difference in their perceptions of their practicum experiences. Qualitative data of candidates, their supervisors and mentors were analyzed by categorizing the data into seven major themes as indicated by the open-ended questions. Consistencies and patterns of responses from candidates, supervisors and mentors were closely observed and monitored.

\section{FINDINGS}

\section{Demographic Information}

Of the 17 supervisors participated in this study, $93.7 \%$ were over 50 years old; $50 \%$ were male and $50 \%$ were female; the majority of them were Caucasian (68.8\%); $50 \%$ were full-time and $50 \%$ part-time; more than half of them $(57.1 \%)$ had over 20 years of P-12 school leadership experience; and half of them had served as practicum supervisors for 5 or more than 5 semesters (See Table 1).

Table 1

\begin{tabular}{|l|c|c|c|c|c|}
\hline \multicolumn{5}{|c|}{ Demographics of 17 Supervisor by Percentages } & \\
\hline Age & $41-45(6.3 \%)$ & $50+(93.7 \%)$ & & & \\
\hline Gender & Male (50\%) & Female (50\%) & & & \\
\hline Ethnicity & Caucasian (68.8) & Afric. Amer.(18.8) & & & \\
\hline Faculty & Full-time (50\%) & Par-time (50\%) & & & \\
\hline Leader Exper. & $1-5(7.1 \%)$ & $6-10(14.4)$ & $11-15(7.1)$ & $16-20(14.3)$ & $20+(57.1 \%)$ \\
\hline Semesters as Supervisor & $1(7.1 \%)$ & $2(6.2 \%)$ & $3(18.8 \%)$ & $4(12.5 \%)$ & $5+(50 \%)$ \\
\hline
\end{tabular}

A total of 13 practicum mentors participated in the study. A majority of them (61.6\%) were over 46 years of age. Most of them were female (69.2\%) and Caucasian (84.6\%). They were either school principals (46.2\%) or 
assistant principals (53.8\%). Many of them were in their first five years of school administration (38.5\%) and had served as practicum mentors for 2 semesters (61.5\%) (See Table 2).

Eighty-three practicum candidates responded to the survey with most of them enrolled in the Master of Education program (75.9\%) and the rest in the leadership add-on program (24.1\%). Most of the candidates were female $(78.3 \%)$, Caucasian $(66.3 \%)$, and held bachelor's degrees $(67.5 \%)$. Seventy-one percent of them were classroom teachers with about half of them (53\%) in elementary schools. Over half of the candidates (60.3\%) were in their first ten years of teaching, and 56.6\% had no school leadership experience. Most candidates said their career goals were to become administrators either at the school level (50.6\%) or at the district level (36.2\%) (See Table 3).

Table 2

\begin{tabular}{|l|c|c|c|c|c|}
\hline \multicolumn{5}{|c|}{ Demographics of 13 Mentors by Percentages } & \\
\hline Age & $36-40(38.4)$ & $46-50(30.8)$ & $50+(30.8)$ & & \\
\hline Gender & Male (30.8) & Female (69.2) & & & \\
\hline Ethnicity & Caucasian (84.6) & Afric. Amer. (7.7) & Hispanic (7.7) & & \\
\hline Position & Principal (46.2) & Asst. Prin. (53.8) & & & \\
\hline Leader. Exper. & $1-5(38.5)$ & $6-10(15.4)$ & $11-15(23)$ & $16-20(7.7)$ & $20+(15.4)$ \\
\hline Semesters as Mentor & $1(0 \%)$ & $2(61.5 \%)$ & $3(15.4 \%)$ & $4(23.1 \%)$ & $5+(0 \%)$ \\
\hline
\end{tabular}

Table 3

\begin{tabular}{|c|c|c|c|c|c|}
\hline \multicolumn{6}{|c|}{ Demographics of 83 candidates by Percentages } \\
\hline Gender & Male $(21.7 \%)$ & Female $((78.3 \%)$ & & & \\
\hline Ethnicity & Caucasian $(66.3 \%)$ & Afric. Amer. (24.1\%) & Hispanic $(9.6 \%)$ & & \\
\hline Program & MED $(75.9 \%)$ & Add-on $(24.1 \%)$ & & & \\
\hline \multirow[t]{3}{*}{ Position } & Teacher $(71 \%)$ & Asst. Prin. (3.6\%) & Principal $(2.4 \%)$ & & \\
\hline & Admin. Asst. (0\%) & Dept. Chair $(7.2 \%)$ & ILT/ALT $(4.8 \%)$ & & \\
\hline & District $(2.4 \%)$ & Other $(8.4 \%)$ & & & \\
\hline Degrees & BA/BS (67.5\%) & $\operatorname{MED}(27.7 \%)$ & Ed.S $(2.4 \%)$ & EdD/PhD (2.4\%) & \\
\hline Level & ES (53\%) & MS (19.3\%) & HS $(26.5 \%)$ & Central $(1.2 \%)$ & \\
\hline Leader. Exper. & $0(56.6 \%)$ & $0-1(12 \%)$ & $1-5(25.4 \%)$ & $6-10(6 \%)$ & \\
\hline Teach. Exper. & $1-5(24.2 \%)$ & $6-10(36.1 \%)$ & $11-15(28.9 \%)$ & $16-20(8.4 \%)$ & $20+(2.4 \%)$ \\
\hline Career Goals & Teacher $(1.2 \%)$ & Sch. Admin. (50.6\%) & Central $(36.2 \%)$ & $\begin{array}{c}\text { Undecided } \\
(2.4 \%)\end{array}$ & Other $(9.6 \%)$ \\
\hline
\end{tabular}

\section{Results of Quantitative Analysis}

All of the 17 items responded to by supervisors, mentors and candidates were organized fewer than five practicum themes of interest: course requirements, quality of assignments, assistance to candidates, reflections to journals, supervisors' school visits, and compliance with ELCC standards. Descriptive statistics of supervisors' responses, mentors' responses and candidates' responses are shown in Table 4, Table 5 and Table 6 respectively. All the mean scores indicate that the responses were above average. The supervisors rated "Reflections to Journals" and "Supervisors' School Visits" high (4.29 and 4.24 respectively), and "Compliance with ELCC Standards" (3.63) low. The mentors' ratings on the "Quality of Assignments" were high (4.58) and on the "Supervisors' School Visits" low (3.38). Candidates' responses showed that the "Compliance with ELCC Standards" and "Quality of Assignments" were high (3.99 and 3.96 respectively) whereas "Supervisors' Visits to Schools" was low (3.07). An examination of the standard deviations indicated that candidates' responses were wider apart (average $\mathrm{SD}=1.14$ ) than those of supervisors' (average $\mathrm{SD}=.74$ ) and mentors' (average $\mathrm{SD}=.92$ ) responses. 
Table 4

\begin{tabular}{|l|c|c|c|c|c|}
\hline \multicolumn{7}{|c|}{ Descriptive Statistics for Supervisors' Responses } \\
\hline \multicolumn{1}{|c|}{ Item } & $\mathbf{N}$ & Minimum & Maximum & Mean & SD \\
\hline Course Requirement & 17 & 3.00 & 5.00 & 4.18 & .64 \\
\hline Quality of Assignments & 17 & 2.50 & 4.75 & 3.66 & .58 \\
\hline Assistance to candidates & 17 & 2.75 & 4.75 & 3.68 & .62 \\
\hline Reflections to Journals & 17 & 3.50 & 5.00 & 4.29 & .56 \\
\hline Supervisor Visits & 17 & 1.00 & 5.00 & 4.24 & 1.16 \\
\hline ELCC Compliance & 17 & 2.17 & 5.00 & 4.24 & .85 \\
\hline
\end{tabular}

Table 5

\begin{tabular}{|l|c|c|c|c|c|}
\hline \multicolumn{7}{|c|}{ Descriptive Statistics for Mentors' Responses } & \multicolumn{1}{c|}{ Mean } & SD \\
\hline \multicolumn{1}{|c|}{ Item } & N & Minimum & Maximum & 3.92 & 1.04 \\
\hline Course Requirement & 13 & 2.00 & 5.00 & 4.58 & .66 \\
\hline Quality of Assignments & 13 & 3.00 & 5.00 & 4.15 & .73 \\
\hline Assistance to candidates & 13 & 2.25 & 5.00 & 3.69 & 1.09 \\
\hline Reflections to Journals & 13 & 1.50 & 5.00 & 3.38 & 1.04 \\
\hline Supervisor Visits & 13 & 2.00 & 5.00 & & .94 \\
\hline ELCC Compliance & 13 & 2.00 & 5.00 & 4.14 & \\
\hline
\end{tabular}

Table 6

\begin{tabular}{|l|c|c|c|c|c|}
\hline \multicolumn{7}{|c|}{ Descriptive Statistics for Candidates' Responses } \\
\hline \multicolumn{1}{|c|}{ Item } & N & Minimum & Maximum & Mean & SD \\
\hline Course Requirement & 83 & 1.00 & 5.00 & 3.82 & 1.21 \\
\hline Quality of Assignments & 83 & 1.00 & 4.75 & 3.96 & 1.08 \\
\hline Assistance to candidates & 83 & 1.00 & 4.75 & 3.65 & 1.05 \\
\hline Reflections to Journals & 83 & 1.00 & 5.00 & 3.60 & 1.12 \\
\hline Supervisor Visits & 83 & 1.00 & 5.00 & 3.07 & 1.46 \\
\hline ELCC Compliance & 83 & 1.50 & 5.00 & 3.99 & .90 \\
\hline
\end{tabular}

Analysis of Variance (ANOVA) was used to analyze if significant differences in the perceptions of practicum experiences existed among the candidates, the supervisors and the mentors. (See Table 7) Post Hoc (Tukey's HSD) Tests were followed up to examine the significant mean differences in between individual groups (See Table 8). No significant difference was found among the responses of the three groups in "Course Requirements", "Assistance to Candidates" and "Compliance with ELCC Standards".

Results of ANOVA indicated that significant difference existed among candidates', supervisors' and the mentors' perceptions in "Quality of Assignments" $(\mathrm{F}(2,110)=3.32$, p <.05). Tukey's HSD analysis revealed that mentors' responses (in 4.5 8, SD .66) were significantly higher than supervisors' responses (in 3.66, sd =.58). Candidates' responses (in 3.96, sd $=1.08$ ) were not significantly different from either of the other two groups.

Results of ANOVA indicated that significant difference existed among candidates', supervisors' and the mentors' perceptions in "Reflections to Journals" $(\mathrm{F}(2,110)=3.07, \mathrm{p}<.05)$. Tukey's HSD analysis revealed that supervisors' responses (in 4.29, sd .56) were significantly higher than candidates' responses (in 3.60, sd = 1.12). Mentors' responses (in $3.69, \mathrm{sd}=1.09$ ) were not significantly different from either of the other two groups.

Results of ANOVA indicated that significant difference existed among candidates', supervisors' and the mentors' perceptions in "Supervisors' School Visits" $(\mathrm{F}(2,110)=5.35, \mathrm{p}<.01)$. Tukey's HSD analysis revealed that supervisors' responses (in 4.24, sd =.75) were significantly higher than candidates' responses (in 3.07, sd = 1, 46). Mentors' responses (in $3.38, \mathrm{sd}=1.04$ ) were not significantly different from either of the other two groups.

One-way Analysis of Variance (ANOVA) was used to analyze if gender, ethnicity, leadership experiences and school level made any difference in the participants' perceptions of practicum experiences. Results of the 
analyses indicated that no significant difference was found in all the classifications of gender, ethnicity, leadership experiences and school level among the candidates', the supervisors' and the mentors' responses.

Table 7

\begin{tabular}{|c|c|c|c|c|c|}
\hline \multicolumn{6}{|c|}{ ANOVA-Comparison of Supervisors', Mentors' and Candidate Responses } \\
\hline Item & & Sum of Sqs. & df & Mean Square & $\mathbf{F}$ \\
\hline Course Requirement & $\begin{array}{c}\text { Between groups } \\
\text { Within groups } \\
\text { Total }\end{array}$ & $\begin{array}{c}1.82 \\
139.68 \\
141.50\end{array}$ & $\begin{array}{c}2 \\
110 \\
112\end{array}$ & $\begin{array}{c}.91 \\
1.27\end{array}$ & .72 \\
\hline Quality of Assignments & $\begin{array}{c}\text { Between groups } \\
\text { Within groups } \\
\text { Total }\end{array}$ & $\begin{array}{c}6.37 \\
105.43 \\
111.80\end{array}$ & $\begin{array}{c}2 \\
110 \\
112\end{array}$ & $\begin{array}{c}3.18 \\
.96\end{array}$ & $3.32 *$ \\
\hline Assistance to Candidates & $\begin{array}{c}\text { Between groups } \\
\text { Within groups } \\
\text { Total }\end{array}$ & $\begin{array}{c}2.84 \\
103.39 \\
106.23 \\
\end{array}$ & $\begin{array}{c}2 \\
110 \\
112\end{array}$ & $\begin{array}{c}1.42 \\
.94\end{array}$ & 1.51 \\
\hline Reflections to Journals & $\begin{array}{c}\text { Between groups } \\
\text { Within groups } \\
\text { Total } \\
\end{array}$ & $\begin{array}{c}6.88 \\
123.02 \\
129.90 \\
\end{array}$ & $\begin{array}{c}2 \\
110 \\
112 \\
\end{array}$ & $\begin{array}{l}3.44 \\
1.12\end{array}$ & $3.07 *$ \\
\hline Supervisor Visits & $\begin{array}{c}\text { Between groups } \\
\text { Within groups } \\
\text { Total }\end{array}$ & $\begin{array}{c}19.24 \\
197.70 \\
216.94\end{array}$ & $\begin{array}{c}2 \\
110 \\
112\end{array}$ & $\begin{array}{l}9.62 \\
1.80\end{array}$ & $5.35^{* *}$ \\
\hline ELCC Compliance & $\begin{array}{c}\text { Between groups } \\
\text { Within groups } \\
\text { Total }\end{array}$ & $\begin{array}{c}2.30 \\
85.59 \\
87.89\end{array}$ & $\begin{array}{c}2 \\
110 \\
112\end{array}$ & $\begin{array}{c}1.15 \\
.80\end{array}$ & 1.44 \\
\hline
\end{tabular}

$* \mathrm{p}=$ or $<.05 \quad * * \mathrm{p}=$ or $<.01$

Table 8

\begin{tabular}{|c|c|c|c|c|c|}
\hline \multicolumn{9}{|c|}{ Post Hoc (Tukey HSD) Multiple Group Comparisons of Means } \\
\hline Dependent Variable & I-Group & J-Group & Mean Difference (I-J) & Std. error & Sig. Level \\
\hline Quality of Assignments & 1 & 2 & .302 & .2606 & .480 \\
& 1 & 3 & -.6131 & & \\
& 2 & 3 & $-.9152^{*}$ & .2815 & .039 \\
& 1 & 2 & $-.6977^{*}$ & .3155 & .950 \\
Reflections to Journals & 1 & 3 & -.0959 & .3897 & .274 \\
& 2 & 3 & .6018 & .3569 & .004 \\
Supervisor Visits & 1 & 2 & $-1.1630^{* *}$ & .3999 & .715 \\
& 1 & 3 & -.3123 & .4939 & .201 \\
\hline
\end{tabular}

Group 1 = Candidates' Response

Group 2 = Supervisors' Responses

$* p=$ or $<.05$

Group 3 = Mentors' Responses

\section{Results of Qualitative Analysis}

An analysis of responses from candidates, supervisors and mentors to the six open ended questions is provided below:

\section{A. Strengths of the current practicum course structure}

Participating candidates considered "hands-on" experience and flexibility as the major strengths in the program. In one candidate's words, "Not assigned specific standards at specific times, this allowed me to participate in a wide variety of standards as they came up in my school". A few candidates also mentioned that they had "knowledgeable and helpful" mentors and/or supervisors throughout their practicum experiences.

Participating supervisors concurred with the candidates regarding the real-life experience during practicum as one strength in the program. In addition, they deemed "Individual support for candidates from supervisor in the 
course and in reflections of practicum activities" as strength of the current practicum program. The high quality of the supervisors was also mentioned by the candidates.

Similar to candidates and supervisors, mentors believed that the key strength of the current program was the fact that students were "encouraged to get a broad base of experiences in the practicum". Additionally, "allowing candidates to participate through their regular work assignments", "flexibility to explore and develop a variety of skills", "example practicum activities...", "...reflection journal on activities", "...case sessions" and the opportunity to work alone were listed as the positive aspects of the program by individual mentors.

\section{B. Weaknesses of the current practicum course structure:}

The main weaknesses of the current practicum pointed out by the participating candidates included the following: lack of communication between students and KSU professors, no consistency in the requirements among KSU supervisors, delay in assigning supervisors and giving directions to practicum candidates in the beginning of each semester, difficulty in getting help from mentors, not enough specified experiences, and too many hours required for each semester.

KSU participating supervisors considered "lack of consistency in implementation among supervisors and mentors" and the lack of "consistency and uniformed experiences among all candidates" as two major weaknesses in the current program. They also mentioned the need "to meet regularly with all candidates together in supervisor's group for clarification, examples, questioning, etc".

Like the participating candidates and the KSU participating supervisors, the mentors also regarded the lack of consistency in practicum requirements among different supervisors as a major weakness in the current program. The other weakness was the lack of time for the candidates to obtain the hours required for the candidates each semester.

\section{Importance of the role of the supervisor in the practicum experience:}

In response to this question, approximately $42 \%$ of the participating candidates perceived the role of the supervisor as very important because they guided the overall experience. However, $30 \%$ of the candidates regarded the supervisor's role as not very active and another $11 \%$ did not see the need for a supervisor. Another group of candidates (15\%) considered mentioned mentor's role was more important because they were at the school site.

The participating supervisors' response results indicated that over half of the supervisors (61\%) considered their role as "very important", "critical" or "vital" because they "monitor the quality, and the type of experiences that the candidate has". Like the candidates, a small group of supervisors (17\%) deemed the mentor's role is the most important.

Part of the participating mentors' response to this question was very similar to the supervisors'. Approximately $64 \%$ of them believed that supervisor's role was "very important regarding guidance, feedback and advice". Like the candidates, a very small percentage of the mentors did not think the supervisor's role as very important. One mentor thought that the supervisor's role as important, "but he/she needs to visit more than once or twice during the practicum so that the student, mentor, and supervisor can talk".

D. Importance of the role of a school mentor in this practicum experience:

The majority of participating candidates (72\%) considered the mentor as very important if he/she "assigns leadership duties on a regular basis". However, several candidates commented that the mentor "must be willing to offer guidance into their daily operations, activities, and leadership philosophy". One candidate wrote that she fulfilled her leadership hours on her own because her mentor was very busy and she hated "bothering her for leadership ideas". 
All participating supervisors regarded mentor's role as the most important and it was "the key to the quality of practice experience of each student" (100\%). As one supervisor put it, "They serve as the direct contact for the local school system that creates opportunities for addressing the standards that are compatible with the needs of the student and the school".

The mentors' response to this question was highly similar to those of the Supervisors'. All participating mentors agreed that their role was the most valuable "because the mentor could provide experiences the university courses could not".

\section{E. Most meaningful practicum activities:}

The participating candidates' responses indicated that the most meaningful experiences were the actual activities since they were "most like the position" they were working toward (68\%). The examples included "leadership opportunities in my school", "...a week in the capacity of department chair and a member of the LSC (what is this?) for a school year", "attending leadership workshops, collaborating with the community, which allowed me to meet some important people", and "budget experiences, testing experiences (helping with coordinating standardized tests)".

The participating supervisors also considered hands-on activities to be most meaningful. In addition, their specified activities were related to ELCC standards 1, 3 and 4. For instance, one supervisor commented that Standard 3 activities allowed "students to firsthand experience in managing resources, scheduling classes, etc". Another response mentioned "school improvement planning, budget experiences, working with parents and community", "activities which enable the student to see the "big picture" of leadership and schooling", "those that get the student involved outside their trained area", and "one on one time with the mentor" were responses from individual supervisors.

Over half of the participating mentors' responses (55\%) echoed those of the candidates and supervisors in that they deemed day to day assignment in the "real world" as most helpful. Activates tied to learning, student discipline, budgeting, and schedule were mentioned by mentors. Another mentor thought that the candidates should "get a little experience with everything (planning, organization, management, curriculum, instruction, public relations, etc)".

\section{F. $\quad$ Suggestions to improve the practicum experience:}

With respect to suggestions to improve the practicum experience, the participating candidates suggested the following: (a) regular communication between supervisors and mentors to "make sure the candidate has been given opportunities to do some administrative work", (b) "specific field experiences to complete", (c) consistent expectations across the board, (d) "embedded experience into each course", (e) slight reduction of the number of hours, and (f) reduction of supervisor's visits to one time or no mandated visit unless needed.

The participating supervisors' suggestions echoed items b, c, and d in the candidates list of suggestions. Additionally, they also suggested providing more training to new KSU supervisors each semester "...in the management of grading and using systems for evaluation" and "educate mentors on providing meaningful and essential experiences for candidates' as well as on "...providing criteria, rationale, and specific policies/procedures for decision making".

Regarding the participating mentors suggestions, they were related to items a and $\mathrm{c}$ in the candidates list of suggestions. In terms of communication, they wanted to "talk with student, mentor, and supervisor to discuss situations that come up and programs and progress". With respect to consistency of assigned activities, one mentioned stated that he would like to "ensure that all participants have equal opportunities at leadership roles". 


\section{G. Additional Findings:}

As a part of the study, the researchers also asked the candidates, supervisors and mentors about their perceptions of the role of the supervisor and mentor, experiences they perceived as most meaningful, and their suggestions for program improvements.

Responses showed that $61 \%$ of the supervisors and $64 \%$ of the mentors felt that the role of the supervisor was very important. In contrast, only $42 \%$ of the candidates had the same opinion. Some candidates considered the role as not very important and a few candidates did not even see the need for a supervisor. A small group of mentors also did not think the supervisor's role as very important, either.

Regarding the role of the mentor, every participating supervisor and mentor deemed the role of the mentor as the most important while the majority of the candidates (72\%) had the similar consideration. A few of the candidates mentioned that the willingness of the mentor to guide the candidates could determine the degree of the success of the candidate's in the practicum experience.

In terms of most meaningful practicum activities, all three groups considered actual activities in the real world as most helpful and meaningful. Each group had specific examples of the leadership activities, and saw how they were related to the six ELCC standards.

Regarding suggestions to improve the program, candidates, supervisors and mentors agreed that there should be more consistent expectations across the board. The candidates and the supervisors also mentioned the need for specific field experiences within the program requirements, and the inclusion of an embedded experience into each course were offered as suggestions. Candidates and mentors also considered regular communication among all parties as a needed improvement.

\section{H. Answers to Research Questions}

1. How do university supervisors perceive the effectiveness of practicum experience in the educational leadership program?

Analyses of quantitative and qualitative data indicated that participating supervisors regarded authenticity of practicum experiences as an effective highlight of the leadership program. Reflections of their actual experiences were professionally recorded in the candidates' practicum journals. They rated highly on their school visitations as a means of providing support to leadership program candidates.

At the same time, university supervisors perceived the ineffectiveness of the program as having a lack of consistency between supervisors and mentors. This resulted in differences in practicum experiences among the program candidates. The supervisors seriously questioned whether practicum activities experienced by some candidates were broad enough to cover all the ELCC standards.

2. How do school mentors perceive the effectiveness of practicum experience in the educational leadership program?

Findings of data analyses indicated that mentors believed the key strength of the educational leadership practicum was the quality of candidates' assignments. This was indicated in the broad base of experiences in the practicum to include allowing candidates to participate through their regular work assignments, flexibility to explore and develop a variety of skills, reflective journals on activities, case study sessions and opportunities to work alone.

Like the supervisors, the mentors also regarded the lack of consistency in practicum requirements from different supervisors as a major weakness in the current program. Other shortcomings were the supervisors' school visits and the lack of time for the candidates to obtain the required number of practicum hours in each semester. 
3. How do program candidates perceive the effectiveness of practicum experience in the educational leadership program?

Participating program candidates perceived real life experiences and flexibility as the major strengths in educational leadership practicum. Since they were directed to describe their practicum experiences as they related to ELCC standards, they felt that their hands-on experiences in school met all the requirements of the ELCC standards.

Candidates identified ineffectiveness of the program practicum to include lack of communication between candidates and supervisors, lack of consistency in the requirements among supervisors, unhelpful school visits by supervisors, and delay in assigning supervisors to candidates in every semester. Additionally, candidates reported both successful and unsuccessful experiences working with practicum supervisors and mentors.

4. Do university supervisors, school mentors and program candidates differ significantly in their perceptions of the effectiveness of practicum experience in the educational leadership program?

A summary of findings from quantitative and qualitative data analyses indicated similarities and differences in the perceived effectiveness of practicum activities among supervisors, mentors and candidates in the following:

First, the perceptions of effectiveness of practicum experiences among the supervisors, mentors and candidates did not significantly differ from one another with the highest rating of effectiveness by mentors, candidates and supervisors in ascending order.

Second, the three groups considered hands-on experiences involving real-world activities as the strength of the program.

Third, all three groups considered the lack of consistency in practicum requirements from different supervisors as a major ineffectiveness in practicum experiences. Some candidates and supervisors also identified lack of communication between candidates and supervisors as ineffective.

Fourth, in the role of a practicum supervisor, the supervisors identified themselves as serving a most significant role in guiding the program activities and candidates. However, supervisors' roles were not perceived favorably by mentors and candidates who questioned the effectiveness of the supervisors' school visits. The value of the supervisor's role in offering practicum experiences was perceived as useful by less than half of the participating candidates.

Fifth, in the role of a practicum mentor, the mentors prided themselves as performing an enormous task of ensuring candidates' exposure to leadership experiences. Both supervisors and candidates considered the role of a mentor in assignment of leadership duties to candidates to be important. Candidates were especially appreciative of the role of the practicum mentor.

Sixth, significant difference was observed between the perceptions of supervisors and mentors in the quality of practicum assignments. Mentors considered the practicum assignments to be of higher quality than the supervisors.

Seventh, significant difference was observed between the perceptions of supervisors and candidates in the requirement of candidates' reflection of practicum experiences in journals. Supervisors considered it an excellent activity while candidates did not perceive this as a very beneficial activity.

Eighth, significant difference was observed between the perceptions of supervisors and candidates as related to the value of the school visits by supervisors. However, supervisors considered school visits to 
candidates to be most helpful to candidates. The candidates themselves considered supervisors' school visits as a waste of time.

5. Do gender, ethnicity, leadership experiences and school level make any difference in supervisors', mentors' and candidates' perception of the effectiveness of practicum experience in educational leadership program?

Results of the quantitative data analyses indicated that no significant difference was found in the perceptions of practicum experiences among all the classifications of gender, ethnicity, leadership experiences and school level of candidates, supervisors and mentors.

\section{DISCUSSION}

The findings of this study identified practicum areas that meet the educational demands of candidates while highlighting practicum areas that need improvement. The study contributes to the knowledge base of the field by drawing upon feedback from university supervisors, school mentors and program candidates to evaluate and improve the practicum experience in the educational leadership program. Program candidates are in the best position to discuss their recent experiences of exposure to the real world. Supervisors and mentors can witness from their first hand experience how effective practicum activities work. Responses from supervisors, mentors and candidates regarding leadership practicum experiences are valuable to program developers in their future program redesign effort. The following observations of responses from supervisors, mentors and candidates merit further discussion:

First, both supervisors and mentors perceived highly of the areas of candidates' practicum experiences they were responsible for. While neither of them criticized the contributions of the other, there was no evidence from the findings to indicate any real appreciation of each other's work. In fact, some supervisors expressed dissatisfaction with mentors' assignments for not covering all required areas while some mentors complained about not receiving clear directions of mentors' roles and responsibilities from supervisors. This is more than a communication problem. Since practicum mentors in Georgia are strictly voluntary, supervisors are only seeking mentors for assistance and cooperation. Supervisors' authority in resolving problems in practicum experiences is limited.

Second, differences between perceptions of candidates and supervisors in practicum experiences extend beyond inconsistency of requirements and lack of communication. While full time educational administrative internship in Georgia is not an option, candidates in practicum must earn practicum hours outside their full time responsibilities in school to fulfill requirements. In such situations, expectations of practicum supervisors may be compromised by lack of some practicum opportunities even though candidates tried so hard to meet expectations. In many instances, candidates' practicum experiences are limited to only observations, rather than direct participation in the leadership function.

\section{RECOMMENDATIONS}

Based on the findings of this study, the following recommendations are made to offer opportunities for improvement of practicum experiences in educational leadership program:

1. It is recommended that all the practicum supervisors meet to discuss the requirements of practicum experiences and the roles and responsibilities of all the stakeholders, including all supervisors, mentors and candidate representatives.

2. All first-time and part-time supervisors need to participate in a program workshop to be prepared to supervise candidates in practicum experiences.

3. A communication mechanism has to be built in this entire process of practicum experience delivery. It should be a three way communication network among the three parties: supervisors, mentors and candidates.

4. Regular meetings of supervisors, mentors and candidates should be scheduled to review the progress of practicum activities and assess anticipated outcomes. 


\section{CONCLUSION}

Practicum experiences of educational leadership program candidates are needed, not only to fulfill ELCC standard requirements, but also to expose program candidates to real-world school leadership experiences. Unfortunately, because of all kinds of conditional limitations, such practicum experiences can only be offered in conjunction with candidates' regular work in school. However, leadership practicum experiences can be well planned with a high collaboration of supervisors, mentors and candidates who have an invested interest in school improvement. In this study, what we learn from the differences of perceptions among supervisors, mentors and candidates is a caution to all stakeholders that we need to do a better job to prepare the next generation of school leaders. Supervisors, mentors and candidates need to form a coalition to explore other options, especially out-of-thebox strategies, to deliver a highly effective practicum program for potential educational leaders.

\section{AUTHOR INFORMATION}

J. Eric Tubbs, author, is Assistant Professor of Educational Leadership in the Bagwell College of Education at Kennesaw State University. He is a former high school and middle school principal. He has leadership experience in state government, private industry and business. Dr. Tubbs received his B. S. degree from The University of Akron, M. A. from California State University, Los Angeles, Ed. S. from Converse College, and obtained his Ed. D. in Educational Leadership from The University of Sarasota Florida. Dr. Tubbs has additional specialized training in school improvement, curriculum and instruction, the superintendence, quantitative research, and other areas of leadership. Dr. Tubbs also served as graduate field experience program coordinator for the Department of Educational Leadership.

\section{REFERENCES}

1. Chance, E. W. (1990). The administrative Internship: Effective Program Characteristics. (ERIC Document Reproduction Service No. ED330113)

2. Creighton, T. B. (2001, November). Toward a leadership practice field. Paper presented at the annual meeting of the University Council for Educational Administration at Cincinnati, OH.

3. Crews, A. C, and Weakley, S. (1995). Hungry for leadership: educational leadership program in the SREB states. Atlanta, GA: Southern Regional Education Board.

4. Daresh, J. C. (1997). Improving principal preparation: A review of common strategies. Bulletin, 81(585), 38.

5. Gantner, M. W, and Halsall, A. (2003, April). Restructuring the administrative internship: strengthening the leader's capacity to influence school improvement through action research. A paper presented to the Annual Meeting of the American Educational Research Association at Chicago.

6. Gupton, S. L. (1998, November). State-mandated reform of programs preparing school principals: One university's experience. Paper presented at the annual meeting of the Mid-South Educational Research Association, New Orleans, LA. (ERIC Document reproduction service No. ED 428438)

7. Henderson, M. (2002). Beginning principal's self-perception of administrative task proficiencies in Georgia elementary schools. Unpublished doctoral dissertation, Georgia Southern University, Statesboro, Georgia.

8. Joachim, P., and Klotz, C. (2002). Interviewing practicing administrators: An underutilized field based instructional strategy. (ERIC Document reproduction Service No.).

9. Kraus, C. M. (1996, April). Administrative training: what really prepares administrators for the job? A Paper presented at the annual meeting of the American Educational Research Association, New York. (ERIC Document Reproduction No. ED 390129)

10. Laing, P. and Bradshaw, L. K. (2003, April). Maximizing positive effective of cohort models in the preparation of approbation of school leaders. A paper presented at the Annual Meeting of the American educational Association at Chicago.

11. Lee, G. V. and Keiffer, V. A. (2003, April). Leadership for school improvement: Fostering the preparation dispositions among aspiring principals. A paper presented at the Annual Meeting of the American educational Association at Chicago. 
12. Lovette, O, K. (1997, November). Principalship preparation programs: The principal's perspective. Paper presented at the annual meeting of the Mid-South Educational Research Association, Memphis, TN. (ERIC Document Reproduction Service No. ED 415780).

13. Tubbs, J. Eric (2008, September). Program Coordinators Disposition Toward Educational Leadership Best Practices: Practicum experiences in Georgia. The Journal of Contemporary Issues in Education Research, $4^{\text {th }}$ quarter, 1 (4), 35-42.

14. Tubbs, J. Eric, \& Chan, T. C. (2006). How to create a quality collaborative educational leadership practicum experience. The Southern Regional Council of Educational Administration Yearbook, p. 43-49.

\section{$\underline{\text { NOTES }}$}


NOTES 